\title{
Modeling Public-Private Partnerships in Disaster Management via Centralized and Decentralized Models
}

\author{
Peiqiu Guan, Jun Zhuang \\ Department of Industrial and System Engineering, University at Buffalo, State University of New York, Buffalo, New York 14260 \\ \{peiqiugu@buffalo.edu, jzhuang@buffalo.edu\}
}

\begin{abstract}
The objective of this paper is to help both public and private sectors make better decisions in defensive 1 resource allocation through public and private partnerships (PPPs). In this paper, efficient PPPs are studied with regard to disaster preparedness using a decentralized model (sequential game where the public sector is the first mover) and a centralized model. This paper identifies the best public investment policies by evaluating the effectiveness of incentive provisions based on the various private strategic responses. This paper also provides insights into understanding (a) how to construct optimal public and private partnerships and (b) whether, when, and to what extent public and private investments in disaster preparedness could form better PPPs. We study the conditions of the private and public sectors' allocation strategies when they are strategic complements or substitutes. We find that the private sector that has a higher target valuation or lives in more risky areas invests more and has higher potential to partner with the public sector. We also compare the decentralized model results with the results of the centralized model to study the efficiency of the PPPs and find that the results are similar when the target valuation or the probability of disasters is small.
\end{abstract}

Keywords: public and private partnerships (PPPs); subsidy; investment; sequential games, centralized model; decentralized model

History: Received on July 16, 2014. Accepted by Editor-in-Chief Rakesh K. Sarin on April 21, 2015, after

2 revisions. Published online in Articles in Advance October 5, 2015.

\section{Introduction}

Natural and man-made disasters impact millions of people all over the world. Over the last decade, as a result of the higher population density in urban areas, more people are affected by natural disasters (Webster et al. 2009), as well as by the increasing terrorism activities (National Consortium for the Study of Terrorism and Responses to Terrorism 2014). Disasters have become a global challenge to both the public sector (federal, state, and local governments) and the private sector (private business companies, nonprofit organizations, individual citizens, and other non-government agencies). For example, British Petroleum spilled 4.9 million barrels of oil into the Gulf of Mexico (U.S. Coast Guard 2011) in 2010, costing more than $\$ 40$ billion in economic losses and incomputable environmental damage to the local area. The Japanese earthquake and the subsequent tsunami and nuclear leak in 2011 resulted in
15,883 deaths, 6,150 injuries, 2,643 missing persons (National Police Agency 2015), as well as a \$235 billion economic loss as estimated by the World Bank (Kim 2011). How to better prepare for those disasters and enhance the resilience of a community (which is defined as the ability of the community to withstand or recover from disasters) remains a challenging issue (RAND 2015).

Although our society is facing serious threats from the disasters, the government cannot function efficiently alone in disaster management, partially because the resilience of the community is jointly determined by many agencies, including federal, state, and local governments and the private sectors (Amin 2004, Hayes and Ebinger 2011). According to the Department of Homeland Security (DHS) (U.S. Government Accountability Office 2006), the "private sector owns approximately $85 \%$ of the nation's critical infrastructure," making public-private partnerships 
"essential" in disaster management. Similarly, according to the Committee on Private-Public Sector Collaboration to Enhance Community Disaster Resilience, National Research Council (2012), "It is essential that citizens and communities work together to anticipate threats, limit their effects, and rapidly restore functionality after a crisis" (p. 1).

Public and private partnerships (PPPs), which are defined as the collaboration between the public and private sectors, have been widely studied in many areas, such as finance (Blanc-Brude et al. 2008) and education (Patrinos and Sosale 2007). In fact, a report of the Federal Emergency Management Agency (FEMA) shows that private sectors have involved and worked closely with the government in all phases of emergency management (Adida et al. 2011, Federal Emergency Management Agency 2013). For example, immediately following the $9 / 11$ attacks in the United States, the 2004 Indian Ocean Tsunami, and the 2008 China Wenchuan earthquake, telecommunications companies sent their resources and mobilized their professional staffs to the disaster zone to help resume local communications systems (Flynn 2007, 2008; Norris et al. 2008), which are very important for rescuing operations in disaster response. Based on the existing successful public and private partnerships in disaster management, Busch and Givens (2012) show that the PPPs in disaster management are drawing attention from the DHS and FEMA. How to systematically study the PPPs has become a hot topic in the field of disaster management in recent years (BlancBrude et al. 2008, Busch and Givens 2012). However, most of the literature focuses on debating the advantages of having PPPs in disaster management or surveying the existing PPPs (Briceno 2009). The development of optimal partnership structures has not been extensively studied in the literature. In this paper, we explore the optimization models to provide insights on how to develop win-win PPPs for both private and public sectors through an optimal resource allocation problem.

How does the government allocate its resources in disaster management? Some literature-for example, Brown et al. (2005, 2006), Bier et al. (2008), Hausken (2008), Hausken et al. (2008), Zhuang (2010), and Golalikhani and Zhuang (2011) - focuses on the government's defensive resource allocations in critical infrastructure protection. Likewise, other literature focuses on the government's role in providing subsidies to private citizens (e.g., see Gruber and Levitt 2011 for public health; Hansen 1983 for education). Provision of incentives has been studied in many areas, including computer security (e.g., free software to computer users; August and Tunca 2006), education (e.g., scholarships, loans, and subsidies to students; Dearden et al. 2005, Schultz 2004), climate change (e.g., subsidies and foreign aid to companies or developing countries to reduce greenhouse gas emissions; Nushiwat 2007), healthcare (e.g., subsidized insurance to patients; Gruber and Levitt 2011), and transportation (e.g., subsidies to support urban public transportation; Dodgson 1986). The provision of incentives to companies and countries is also studied in environmental economics literature-for example, to the companies that control pollution in environmental economics and to developing countries in foreign aid (Kriechel and Ziesemer 2009). However, incentive provisions to the private sector from the government in disaster management have not been studied extensively. Thus, in this paper, we study the public sector's role in providing subsidies to the private sector.

In stutying the interaction between the public and private sectors in disaster management, game theory is a proper tool (Shubik 1955) to study the strategic interactions among intelligent, rational decision makers. Game theory can help emergency managers make better decisions by considering what other stakeholders are likely to do (Myerson 1997). Game theory has been widely used in economics, political science, psychology, logic, and biology (Fudenberg and Tirole 1991), and it has been used to guide governmental practices, sometimes even in the absence of empirical validation (e.g., nonempirically tested game models were used to design U.S. government auctions to sell $\$ 42$ billion worth of access to the wireless spectrum from 1994 to 2001; see McMillan 2003). There is a growing literature studying game theory in disaster management (e.g., Zhuang and Bier 2007, Azaiez and Bier 2007, Wang and Bier 2011, Cheung and Zhuang 2012, Samuel and Guikema 2012, Shan and Zhuang 2014). In this paper, besides the game model (decentralized model), we also study the social planner model (centralized model), which optimizes the effects from the whole society prospects, to identify the efficient PPPs in disaster management. 
In this paper, we study how to form better PPPs through the best public and private resource allocation strategies. In the decentralized model, the interactions between the private and public sectors are modeled in a sequential-move game, where the private sector is assumed to be the second mover, whereas the interactions between the private and public sectors are assumed to be simultaneous in the centralized model. The public sector's action is to provide subsidies to the private sector while the private sector makes private investment. For example, the public sector may provide certain subsidies (e.g., tax reductions, food, water, training, drills) to the private sector while the private sector invests in disaster preparedness, such as purchasing house insurance (Kunreuther 2002, Grace et al. 2003); reenforcing houses (e.g., boarding up windows and doors); ordering and storing water and food supplies; participating in exercises, drills, and training; or relocating to less hazardous areas (Lindell and Perry 2000, Lindell and Whitney 2000, Keohane and Zeckhauser 2003).

The rest of the paper is organized as follows: §2 introduces the notation and assumptions, $\$ 3$ proposes the optimization models for both the public and private sectors and defines two kinds of damage functions: exponential and ratio forms, and $\S 4$ studies the decentralized model and illustrates the model results with considerations of both exponential and ratio damage functions. Section 5 studies the centralized (social planner) model, illustrates the model with considerations of the ratio damage function, and compares the decentralized and centralized models with consideration of the ratio damage function both analytically and numerically; $\S 6$ concludes the paper and proposes some ideas for further research. The appendix provides proofs for the propositions.

\section{Notations and Assumptions}

The notations throughout the paper are defined in Table 1, including two decision variables, five model parameters, and five functions.

In PPPs, the private sector is defined as any nongovernment organization or individual (e.g., private business companies, nonprofit organizations, individual citizens, other nongovernment agencies), and the public sector is defined as any level of government agency (e.g., federal, state, local governments).

\begin{tabular}{cl} 
Table 1 & Notations \\
\hline Notation & \\
\hline $\begin{array}{l}\text { Decision variables } \\
s \geq 0\end{array}$ & Public subsidy \\
$p \geq 0$ & Private investment \\
$\left(s^{*}, p^{*}\right)$ & $\begin{array}{c}\text { Subgame-perfect Nash equilibria of a sequential game } \\
\text { (decentralized model) }\end{array}$ \\
$\left(s^{* *}, p^{* *}\right)$ & Optimal solutions of the centralized model \\
Parameters & The private target valuation \\
$V \geq 0$ & The public target valuation \\
$V \geq 0$ & Investment effectiveness coefficient \\
$\gamma \geq 0$ & Probability disaster occurs \\
$P_{d} \in[0,1]$ & Defense inherent level \\
$A>0$ & \\
Functions & The damage-level function, $0 \leq P(s, p) \leq 1$ \\
$P(s, p)$ & Expected loss and cost of the private sector \\
$L_{P}(s, p)$ & Expected loss and cost of the public sector \\
$L_{G}(s, p)$ & Expected loss and cost in the social planner model \\
$L(s, p)$ & (centralized model) \\
$\hat{p}(s)$ & Private sector's best response function \\
\hline
\end{tabular}

In this paper, we first study the efficient PPPs through a sequential game model between the public and private sectors, which are assumed to be rational. The public sector with a target valuation $V$ is assumed to move first by choosing the subsidy $s$. The damage level of the property $P(s, p)$ would be reduced by the public subsidy $s$, but it would generate an investment cost of $s$. In the decentralized model, the goal of the public sector is to minimize its expected loss and investment cost, $L_{G}(s, p)=$ $P_{d} P(s, p) V+s$. In the decentralized model, as the second mover, the private sector invests $p$ resources with a private investment cost $p$ to protect the target with the valuation of $v$ after observing the public sector's decision. The objective of the private sector is also to minimize its expected loss and cost $L_{P}(s, p)$, which is equal to the summation of the expected damage $P_{d} P(s, p) v$ and the investment cost $p$. To obtain the optimal PPPs minimizing the total expected loss and cost $L(s, p)$, we also study PPPs from a social planner's perspective in a centralized model.

The probability that a disaster occurs, $P_{d}$, is assumed to be independent of either public or private investments. For example, whether an earthquake happens would not depend on whether the public or private sectors invest in preparedness. Only damage function $P(s, p)$ is assumed to be jointly impacted by the public and private investments. The damage level 
is assumed to be continuous, twice differentiable, and to have diminishing marginal returns with respect to the public subsidy $s$ and the private investment $p$. The greater the investments of the public and private sectors in disaster preparedness, the less damage to public and private targets. Thus, public subsidy $s$ and private investment $p$ are assumed to jointly reduce the damage level of the target $P(s, p)$; that is,

$$
\begin{gathered}
\frac{\partial P}{\partial s} \leq 0, \quad \frac{\partial P}{\partial p} \leq 0, \\
\frac{\partial^{2} P}{\partial s^{2}} \geq 0, \quad \frac{\partial^{2} P}{\partial p^{2}} \geq 0, \quad \frac{\partial^{2} P}{\partial p \partial s} \geq 0 .
\end{gathered}
$$

\section{Models and the Damage-Level Function Definition}

\subsection{Optimization Models}

The goal of the private sector is to minimize its total expected loss $P_{d} P(s, p) v$ and investment cost $p$ :

$$
\min _{p \geq 0} L_{P}(s, p)=P_{d} P(s, p) v+p .
$$

The objective of the public sector is to minimize its expected loss $P_{d} P(s, p) V$ and investment cost $s$ :

$$
\min _{s \geq 0} L_{G}(s, p)=P_{d} P(s, p) V+s .
$$

\subsection{Definition of Damage-Level Function: Exponential and Ratio Forms}

Following Bier et al. (2008), Hao et al. (2009), and Wang and Bier (2011), we model the damage-level function $P(s, p)$ as exponentially decreasing in public subsidy $s$ and private investment $p$; that is,

$$
P(s, p)=\exp \left[-\gamma(\underbrace{s+p}_{\begin{array}{c}
\text { Single } \\
\text { effects }
\end{array}}+\underbrace{s p}_{\begin{array}{c}
\text { Jint } \\
\text { effects }
\end{array}})\right] .
$$

Following Zhuang and Bier (2007) and Hausken and Zhuang (2012), we also consider the damagelevel function $P(s, p)$ in a ratio form:

$$
P(s, p)=\frac{1}{A+\gamma(\underbrace{s+p}_{\begin{array}{c}
\text { Single } \\
\text { effects }
\end{array}}+\underbrace{s p}_{\begin{array}{c}
\text { Joint } \\
\text { effects }
\end{array}})},
$$

where $\gamma$ is the investment effectiveness coefficient and $A$ is the defense inherent level. The parameters $s$ and $p$ represent the single effect of the investments, and $s p$ models the investment joint effects between the private investment and the public subsidy. The public and private sectors can enjoy the joint effects if both of them invest positively. The joint effect term is used to model the additional benefits of the PPPs to the public and private sectors. For example, if the public sector provides positive subsidy $s>0$, to receive the extra benefits from the joint effects of partnerships, the private sector has to invest positively. The more the private sector receives additional partnership benefits, the more it invests with a slope of $s(s p)$. Otherwise, if $s=0$, the private sector cannot receive any additional benefits from the partnerships.

\section{Decentralized PPPs Model}

4.1. The Best Response and Equilibrium Strategy

Since the private sector is assumed to be the second mover in a sequential-move game, we first study the private sector's best response $\hat{p}(s)$, which is defined as follows:

$$
\hat{p}(s) \equiv \underset{p \geq 0}{\arg \min } L_{P}(s, p) .
$$

The private sector's best response function produces an optimal strategy for the private sector that minimizes its total expected loss and cost by taking the public sector's strategy $s$ as given.

Proposition 1. The private best response function $\hat{p}(s)$ is given by

$$
\hat{p}(s)= \begin{cases}0 & \text { if }\left.\frac{\partial L_{P}(s, p)}{\partial p}\right|_{p=0} \geq 0, \\ \left\{p: \frac{\partial L_{P}(s, p)}{\partial p}=0\right\} & \text { if }\left.\frac{\partial L_{P}(s, p)}{\partial p}\right|_{p=0}<0,\end{cases}
$$

where $\partial L_{P}(s, p) / \partial p$ is the total marginal payoff for the private sector.

Remark. Proposition 1 shows that (a) the private sector invests if and only if the marginal loss reduction is negative $\left(\partial L_{P}(s, p) /\left.\partial p\right|_{p=0}<0\right)$ at zero investment level. That is, given a certain level of public subsidy $s$, if the private investment $p$ becomes positive, the private sector's expected loss and cost decrease. (b) If $p$ is positive, the first-order condition on $\partial L_{P}(s, p) / \partial p=0$ yields the optimal level of $p$. 
We note that when the private sector's marginal loss reduction is equal to zero, it yields the optimal level of the private sector's response.

After substituting the private best response function $\hat{p}(s)$ into the public sector's optimization model (3), the public sector's optimization can be written as follows:

$$
\hat{L}_{G}(s) \equiv \min _{s \geq 0} L_{G}(s, \hat{p}(s))=P(s, \hat{p}(s)) P_{d} V+s .
$$

Taking the derivative of the damage-level function $P(s, \hat{p}(s))$ in Equation (8) with respect to $s$, we have

$$
\frac{\partial P(s, \hat{p}(s))}{\partial s}=\frac{\partial P(s, \hat{p}(s))}{\partial s}+\frac{\partial P(s, \hat{p}(s))}{\partial p} \cdot \frac{d \hat{p}(s)}{d s},
$$

where $d \hat{p}(s) / d s$ could be derived from Equation (7). Since $d \hat{p}(s) / d s$ is indeterminate, it can be either negative or positive. As a result, the overall effect of the public subsidy on the equilibrium private investment cannot be decided. From the assumptions in Equation (1), we note that $\partial P / \partial s \leq 0$ and $\partial P / \partial p \leq 0$. Therefore, the effect of public subsidy in Equation (9) consists of two parts: a direct reduction in the damage function as a result of subsidy $s$, reflected by $\partial P(s, \hat{p}(s)) / \partial s$, and an indirect change (reduction or increase) in the damage-level function as a result of the modified private investment, reflected by $(\partial P(s, \hat{p}(s)) / \partial p) \cdot(d \hat{p}(s) / d s)$. The second part of the effect cannot be ignored; otherwise, the subsidy may crowd out the private investment $(d \hat{p}(s) / d s \leq 0$ such that $(\partial P(s, \hat{p}(s)) / \partial p) \cdot(d \hat{p}(s) / d s \geq 0))$.

Proposition 2. The necessary conditions for the solution to the public sector's optimization problem (8) are given below:

1. If $s^{*}>0$, then $\partial L_{G}(s, \hat{p}(s)) /\left.\partial s\right|_{s=0}<0$,

2. If $s^{*}=0$, then $\partial L_{G}(s, \hat{p}(s)) /\left.\partial s\right|_{s=0} \geq 0$,

where $\partial L_{G}(s, \hat{p}(s)) / \partial s=(\partial P(s, \hat{p}(s)) / \partial s) P_{d} V+1$ is the total marginal payoff for the public subsidy.

Remark. Proposition 2 indicates that if the public sector provides positive subsidy to the private sector at equilibrium, then the public sector's marginal payoff is negative. In other words, the public sector can improve its objective (the public expected loss and cost decrease) as the public subsidy $s$ becomes positive when the public sector's marginal payoff is negative. Otherwise, the public subsidy $s$ remains zero.
Definition 1. In a sequential game, we call a collection of strategies $\left(s^{*}, p^{*}\right)$ a subgame-perfect Nash equilibrium (SPNE) if and only if both Equations (10) and (11) are satisfied:

$$
\begin{gathered}
s^{*}=\underset{s \geq 0}{\arg \min } L_{G}(s, \hat{p}(s)), \\
p^{*}=\hat{p}\left(s^{*}\right)=\underset{p \geq 0}{\arg \min } L_{P}\left(s^{*}, p\right) .
\end{gathered}
$$

We obtain the SPNE using backward induction: First, we calculate the private sector's best response function $\hat{p}(s)$ from Proposition 1; and then we substitute it into the public sector's optimization model (3) and solve for the public sector's strategy $s^{*}$. Finally, we obtain the private sector's best strategy by substituting $s^{*}$ back into the private sector's best response function, $p^{*}=\hat{p}\left(s^{*}\right)$.

\subsection{Analytical Solutions with the Exponential Damage-Level Function}

4.2.1. Best Response and SPNE. In this section, we first study the private sector's best response, $\hat{p}(s)$. Using the exponential damage-level function in Equation (4) in §3.2, the private sector's optimization model becomes

$$
\min _{p \geq 0} L_{P}(s, p)=\exp [-\gamma(s+p+s p)] P_{d} v+p ，
$$

and the public sector's optimization model (3) becomes

$$
\min _{s \geq 0} L_{G}(s, p)=\exp [-\gamma(s+p+s p)] P_{d} V+s .
$$

By applying Proposition 1, the private sector's best response function $\hat{p}(s)$ is given by

$$
\hat{p}(s)= \begin{cases}\frac{\ln \left\{P_{d} v \gamma(1+s)\right\}-\gamma s}{\gamma(1+s)} & \text { if } P_{d} v>\frac{e^{\gamma s}}{\gamma(1+s)}, \\ 0 & \text { otherwise. }\end{cases}
$$

According to the private sector's best response function in Equation (14), we note that the private sector's best response is to do nothing if $P_{d} v$ is small, especially if $P_{d} v \leq e^{\gamma s} /(\gamma(1+s))\left(P_{d} v\right.$ represents the private sector's expected losses once the disaster happens and its target is totally destroyed). For example, people may not want to spend money in protecting 
their properties against flooding if they live in high places where flooding barely happens or if their properties are valueless. We also note that the private sector's best response $\hat{p}(s)$ increases as the private target valuation $v$ and the probability of disaster $P_{d}$ increase. This implies that the private sector that locates in the hazardous area with a high-valued target would have a greater potential to partner with the public sector.

Proposition 3. Using the exponential damage level function as specified in Equation (4), the private sector's best response function, $\hat{p}(s)$,

- monotonically increases in subsidy s or $\partial \hat{p}(s) / \partial s>0$ (strategic complements) if and only if

$$
\frac{e^{\gamma s}}{\gamma(1+s)}<P_{d} v<\frac{e^{1-r}}{\gamma(1+s)} \quad \text { and }
$$

- monotonically decreases in subsidy s or $\partial \hat{p}(s) / \partial s<0$ (strategic substitutes) if and only if

$$
P_{d} v>\max \left(\frac{e^{\gamma s}}{\gamma(1+s)}, \frac{e^{1-r}}{\gamma(1+s)}\right) .
$$

Remark. Proposition 3 states that the positive private sector's best response (under the condition of $\left.P_{d} v>e^{\gamma s} /(\gamma(1+s))\right)$ and the public subsidy $s$ can be either strategic complements or strategic substitutes. First, if $P_{d} v$ is moderate, the private sector's best response $\hat{p}(s)$ first increases if $e^{\gamma s} /(\gamma(1+s))<$ $P_{d} v<e^{1-r} /(\gamma(1+s))$ and then decreases if $P_{d} v>$ $\max \left(e^{\gamma s} /(\gamma(1+s)), e^{1-r} /(\gamma(1+s))\right)$ as $s$ increases. Second, if $P_{d} v$ is large, such that $P_{d} v>\max \left(e^{\gamma s} /(\gamma(1+s))\right.$, $\left.e^{1-r} /(\gamma(1+s))\right)$ for any given public subsidy level, the private sector's best response $\hat{p}(s)$ decreases in $s$, which means that the private sector's best response and the public subsidy are strategic substitutes to each other for any given public subsidy level.

Figure 1, panels (a)-(c), demonstrates the results in Proposition 3 and compares the best responses of the private sector with different target valuations (low valuation $v=0.5$, moderate valuation $v=5$, and high valuation $v=50$ ) to the given public sector's strategy (subsidy $s$ ).

Figure 1, panel (a) shows that the best response of the private sector with low target valuation $(v=$ $0.5)$ is to invest nothing. The reason is that the private sector's total expected damages, $P_{d} v=0.25$, are small. Thus, according to the private sector's best response function in Equation (14), the private sector's best response is to do nothing by the given public sector's subsidy level $s \in[0,15]$. Panel (b) illustrates the moderate range of $P_{d} v\left(P_{d} v=\right.$ $0.5 \times 5=2.5)$. The private sector will do nothing when $s \leq 4.5\left(P_{d} v \leq e^{\gamma s} /(\gamma(1+s))\right)$, and it will first increase when $s \in(4.5,8) \quad\left(e^{\gamma s} /(\gamma(1+s))<P_{d} v<\right.$ $\left.e^{1-r} /(\gamma(1+s))\right)$ and then decrease when $s \in[8,15]$ $\left(P_{d} v>\max \left(e^{\gamma s} /(\gamma(1+s)), e^{1-r} /(\gamma(1+s))\right)\right)$. The public and private sectors are either strategic complements or substitutes, which explains the results in Proposition 3. Panel (c) illustrates that the private sector's best response decreases in the public sector's subsidy $s \in[0,15]$ when the $P_{d} v$ are large, which implies that the private best response and the public subsidy are strategic substitutes to each other.

Figure 1 (Color online) Private Sector's Best Response with Three Different Target Valuations at the Baseline Value of $\gamma=0.1, P_{d}=0.5$

(a) $v=0.5$

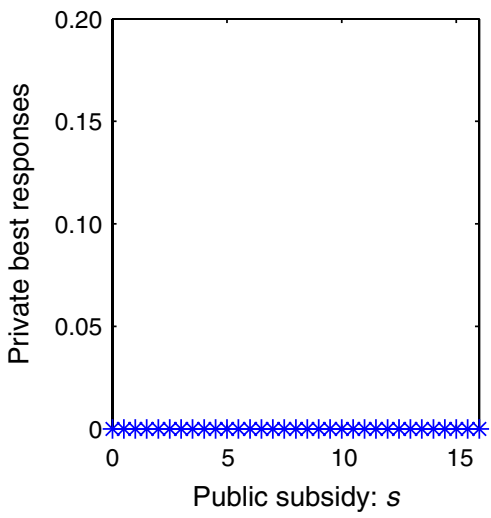

(b) $v=5$

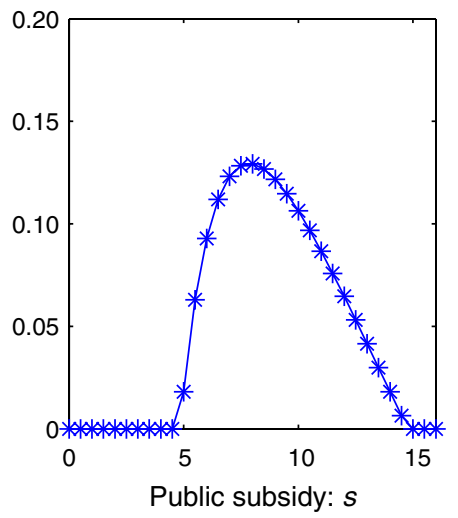

(c) $v=50$

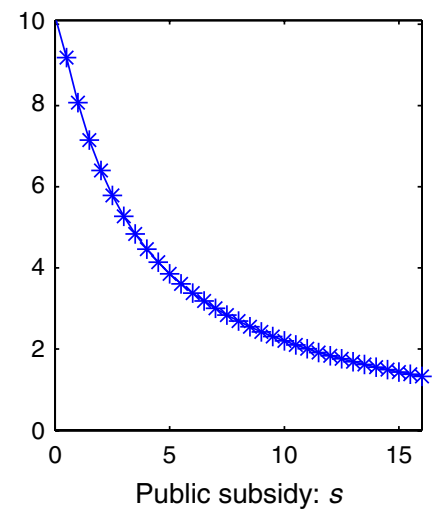


To obtain the equilibrium solution, we substitute the private sector's best response function in Equation (14) into the public sector's optimization model (13), and we have

$$
s^{*}=\underset{s \geq 0}{\operatorname{argmin}} \begin{cases}\frac{V}{\gamma v(1+s)}+s & \text { if } P_{d} v>\frac{e^{\gamma s}}{\gamma(1+s)}, \\ \exp [-\gamma s] P_{d} V+s & \text { if } P_{d} v \leq \frac{e^{\gamma s}}{\gamma(1+s)} .\end{cases}
$$

Thus, with the public sector's equilibrium solution $s^{*}$ in Equation (15) and the private sector's best response function $p^{*}=\hat{p}\left(s^{*}\right)$ in Equation (14), we have four cases of equilibrium solutions, as provided in Proposition 4.

Proposition 4. Using the exponential damage-level function as specified in Equation (4), we present four cases of equilibrium strategies $\left(s^{*}, p^{*}\right)$ and their corresponding optimal conditions:

Case 1: $\left(s^{*}, p^{*}\right)=\left(\sqrt{\frac{V}{\gamma v}}-1, \frac{\ln \left\{P_{d} \sqrt{v \gamma V}\right\}-\gamma(\sqrt{V /(\gamma v)}-1)}{\gamma \sqrt{V /(\gamma v)}}\right)$ if $\mathrm{O}_{1}$,

Case 2: $\left(s^{*}, p^{*}\right)=\left(0, \frac{1}{\gamma} \ln \left\{\gamma P_{d} v\right\}\right)$ if $O_{2}$,

Case 3: $\left(s^{*}, p^{*}\right)=\left(\frac{1}{\gamma} \ln \left\{\gamma P_{d} V\right\}, 0\right)$ if $O_{3}$,

Case 4: $\left(s^{*}, p^{*}\right)=(0,0)$ if $\mathrm{O}_{4}$,

where the optimal conditions $O_{i}, i=1,2,3,4$ are defined in Equations (33)-(36) in Appendix A.4.

Remark. Cases 1-4 in Proposition 4 show all the possible SPNE strategies for the public and private sectors. In particular, the private sector would not participate in the PPPs at equilibrium $\left(p^{*}=0\right)$ in Cases 3 and 4 , whereas the public sector would provide zero subsidy at equilibrium in Cases 2 and 4. Both public and private sectors invest positively in Case 1. In Cases 2 and 3, either positive private investment or public subsidy is provided. According to Equation (16), we note that both public and private sectors would strengthen their efforts in the PPPs if their own target valuations increase (the public subsidy $s^{*}$ increases as $V$ increases, and the private investment $p^{*}$ increases as $v$ increases). In particular, for Case 1 , the public investment increases in public target valuation $V$ and decreases in the private target valuation $v$.
The private investment increases in private target valuation $v$ and the probability of the disaster $P_{d}$; it decreases in the public target valuation $V$. For Case 2 (or Case 3), if the public sector provides zero subsidy $s^{*}=0$ (or the private sector provides zero private investment $p^{*}=0$ ), the private sector's strategy (the public sector's strategy) would not be affected by the public sector (the private sector).

4.2.2. Sensitivity Analyses. Based on a set of baseline values $v=10, V=30, \gamma=0.1$, and $P_{d}=0.5$, we study how the equilibrium solutions are sensitive to the model parameters' change. The following model parameters change one at a time in the analyses: the private sector's target valuation $(v)$ and public target valuation $(V)$ in Figure 2 and the investment effectiveness coefficient $(\gamma)$ and the probability of disaster occurrence $\left(P_{d}\right)$ in Figure 3.

Figure 2, panel (a) shows that the public subsidy $s$ first increases and then decreases as the private target valuation $v$ increases, whereas the public sector always increases the subsidy as the public target valuation $V$ increases in panel (b). From panels (a) and (b), we note that (zero subsidy, zero private investment) could be an equilibrium if the private target valuation $v$ or the public target valuation $V$ is low. In panel (b), we note that the high level of subsidy would crowd out the private investment as the public target valuation $V$ increases. Figure 2 shows that the public (private) sector's expected loss and cost increase as the public (private) target valuation increases or as the private (public) sector's target valuation decreases.

Figure 3, panel (a) shows that the public and private sectors would not invest if the probability of disaster is low $\left(P_{d}<0.25\right)$. Both the public and private sectors invest positively at the equilibrium if the probability of disaster $P_{d}$ is large. Interestingly, according to the results of Case 1 in Proposition 4, we note that if both the public and private sectors provide positive investments, only the private investment increases in the probability of disaster $P_{d}$, and the public subsidy would not be affected by $P_{d}$. In panel (b), both the public and private sectors would not invest $\left(s^{*}=0, p^{*}=0\right)$ if the investment is not effective at all $(\gamma=0)$, leading to the highest public and private expected losses and costs. The public 
Figure 2 (Color online) Comparison of the Public and Private Sectors' Optimal Strategies and Expected Payoffs as Functions of the Private and Public Target Valuations $V$ and $V$

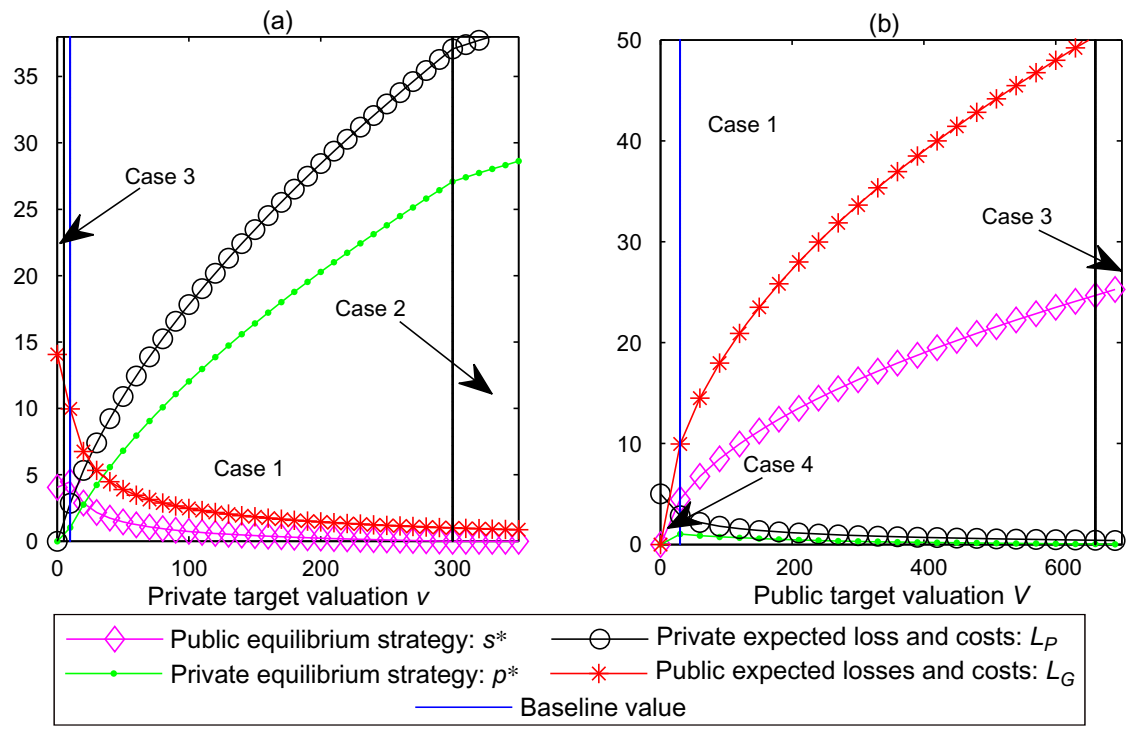

Figure 3 (Color online) Comparison of the Public and Private Sectors' Optimal Strategies and Expected Payoffs as Functions of the Probability of Disaster $P_{d}$ and the Investment Effectiveness Coefficient $\gamma$

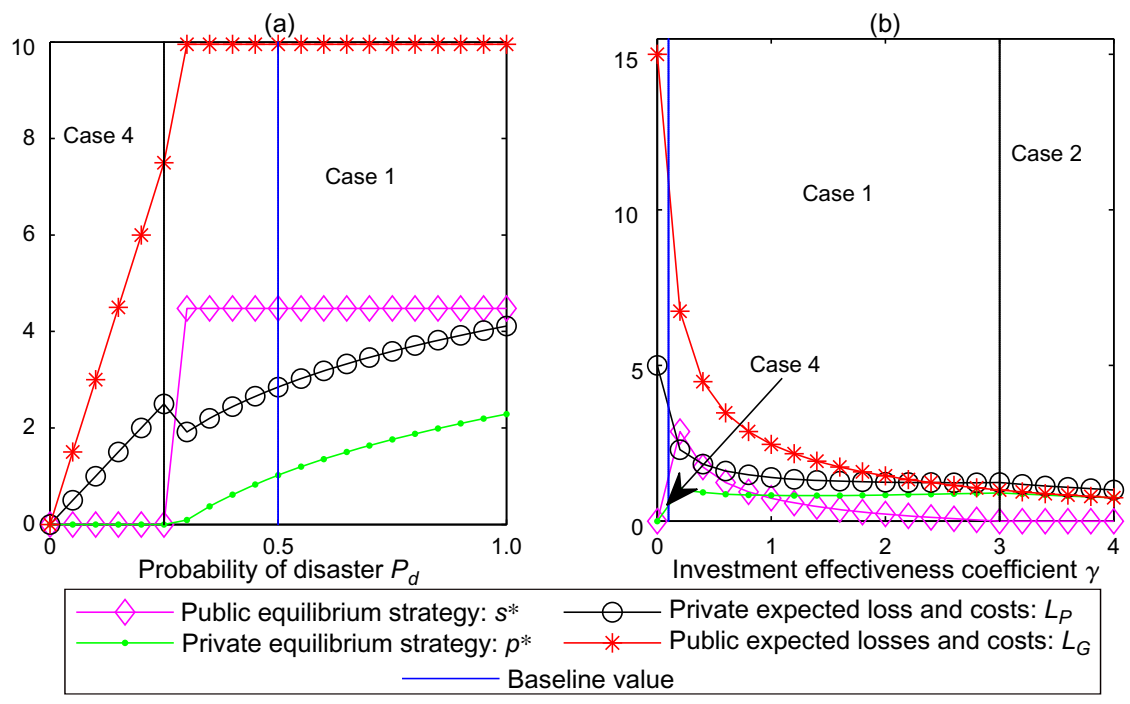

and private sectors first increase and then decrease their investments at equilibrium as $\gamma$ increases while both the public and private expected losses and costs decrease as the investments become more efficient.

\subsection{Analytical Solutions with the Ratio Damage-Level Function}

Based on the private sector's best response function defined in Proposition 1, we have the private sector's best response function $\hat{p}(s)$ as follows:

$$
\hat{p}(s)= \begin{cases}\sqrt{\frac{P_{d} v}{\gamma(1+s)}-\frac{A+\gamma s}{\gamma(1+s)}} & P_{d} v>\frac{(A+\gamma s)^{2}}{\gamma(1+s)}, \\ 0 & P_{d} v \leq \frac{(A+\gamma s)^{2}}{\gamma(1+s)} .\end{cases}
$$

Substituting the private sector's best response function in Equation (17) into the public sector's optimization model (3), and based on the SPNE defined 
in Definition 1 for the decentralized model, we can obtain the public and private sectors' equilibrium solutions. To simplify the problem, we let $A=1$.

Proposition 5. Using the ratio damage-level function shown in Equation (5), we present equilibrium solutions for the decentralized model as four cases:

Case 1: $\left(s^{*}, p^{*}\right)=\left(\sqrt[3]{\frac{V^{2} P_{d}}{4 \gamma v}}-1, \sqrt[3]{\frac{2 v^{2} P_{d}}{\gamma V}}-1\right)$ if $O_{1}^{r}$,

Case 2: $\left(s^{*}, p^{*}\right)=\left(0, \sqrt{\frac{P_{d} v}{\gamma}}-1\right)$ if $\mathrm{O}_{2}^{r}$,

Case 3: $\left(s^{*}, p^{*}\right)=\left(\sqrt{\frac{P_{d} V}{\gamma}}-1,0\right)$ if $O_{3}^{r}$,

Case 4: $\left(s^{*}, p^{*}\right)=(0,0)$ if $\mathrm{O}_{4}^{r}$,

where $O_{i}^{r}(i=1,2,3,4)$ defined in Equations (50)-(53) is the corresponding condition for the equilibrium solution of Case $i$.

\section{Centralized PPP Model}

\subsection{The Optimal Strategy}

A social planner model is developed in this section to attempt to determine the best possible results for both public and private sectors. It is defined as follows:

$$
L(s, p)=P_{d} P(s, p) V+p+s .
$$

Thus, the optimal solution of the centralized model $\left(s^{* *}\right.$ and $\left.p^{* *}\right)$ is defined as follows:

$$
\left(s^{* *}, p^{* *}\right)=\underset{s \geq 0, p \geq 0}{\arg \min } L(s, p)=P_{d} P(s, p) V+p+s .
$$

Proposition 6. The necessary conditions for the public and private sectors' optimal strategies $\left(s^{* *}, p^{* *}\right)$ in Equation (20) are given as follows:

1. If $s^{* *}>0$, then $\partial L\left(s, p^{* *}\right) /\left.\partial s\right|_{s=0}<0$,

2. If $p^{* *}>0$, then $\partial L\left(s^{* *}, p\right) /\left.\partial p\right|_{p=0}<0$,

3. If $s^{* *}=0$, then $\partial L\left(s, p^{* *}\right) /\left.\partial s\right|_{s=0} \geq 0$,

4. If $p^{* *}=0$, then $\partial L\left(s^{* *}, p\right) /\left.\partial p\right|_{p=0} \geq 0$,

where $\partial L(s, p) / \partial s$ and $\partial L(s, p) / \partial p$ are the total marginal payoffs for the public subsidy and private investment, respectively.

\subsection{Analytical Solutions with the Ratio Damage-Level Function}

To reduce the complexity of the analytical solution, a ratio damage-level function is used in this section instead of the exponential damage-level function. With the damage-level function defined in Equation (5), the centralized model in Equation (20) becomes

$$
\begin{aligned}
\left(s^{* *}, p^{* *}\right) & =\underset{p \geq 0, s \geq 0}{\arg \min } L(s, p) \\
& =\frac{P_{d} V}{A+\gamma(s+p+s p)}+p+s .
\end{aligned}
$$

Similar to $\S 4.3$, to simplify the problem, we let $A=1$. The optimal solution to the social planner's centralized model (21) is as follows.

Proposition 7. Using the ratio damage-level function shown in Equation (5), we present optimal solutions for the centralized model as the following two cases:

Case 1: $\left(s^{* *}, p^{* *}\right)=\left(\sqrt[3]{\frac{P_{d} V}{\gamma}}-1, \sqrt[3]{\frac{P_{d} V}{\gamma}}-1\right)$, $P_{d} V>\gamma$

Case 4: $\left(s^{* *}, p^{* *}\right)=(0,0), \quad P_{d} V \leq \gamma$.

From Equation (22), we note that the private and public sectors would invest more in disaster preparedness if (a) the expected loss $P_{d} V$ of the community is greater than $\gamma$-in other words, the investment would be increased in disaster preparedness if the community suffers high disaster risk; and (b) the investment is less efficient. If the investment is less efficient, then more money would need to be invested to achieve the target of reducing risk. Equation (22) also shows that the strategies of Case $2\left(s^{* *}=0, p^{* *}>0\right)$ and Case $3\left(s^{* *}>0, p^{* *}=0\right)$ are impossible in the centralized model.

\subsection{Comparison of the Decentralized Model and Centralized Model with the Ratio Damage-Level Function}

On the basis of the analytical solution of the decentralized model in Proposition 5 and the analytical solution of the centralized model in Proposition 7, we compare the analytical solutions of the decentralized and centralized models case by case. 
In comparing the analytical solutions in both models, we find a commonplace of the solutions in the two models: for the solutions in Case 1 in both models, both public and private investments increase as the probability of disaster $P_{d}$ increases, and the investment effectiveness coefficient $\gamma$ decreases. There are differences in the solutions of the two models. In particular,

- For Case 1, with the consideration of the sequential move between two decision makers in the decentralized model, the public investment increases in public target valuation $V$ and decreases in the private target valuation $v$, and the private investment increases in private target valuation $v$ and decreases in the public target valuation $V$. Both the public and private investments increase in the target valuation in the centralized model. In the centralized model, to achieve the social optimum, the decision maker is suggested to invest a positive amount of investment even if his target valuation is zero. This cannot be true in the decentralized model, because no one would invest to protect targets with zero valuation. Thus, although few examples of the centralized model exist in reality, PPPs can be better displayed under the decentralized model.

- For Cases 2 and 3, in the decentralized model, if the public sector provides zero subsidy $\left(s^{*}=0\right.$ or $\left.s^{* *}=0\right)$, the private sector's strategy $\left(p^{*}\right)$ does not depend on the public target valuation $V$; if the private sector does not invest $\left(p^{*}=0\right.$ or $\left.p^{* *}=0\right)$, the public sector's strategy $\left(s^{*}\right)$ is not impacted by the private sector's information. However, in the centralized model, Cases 2 and 3 do not exist, which means that either the private sector or the public sector would not invest alone.

With the model parameters' baseline value set as $P_{d}=0.5, \gamma=1, V=40$, we compare the numerical illustrations for the public and private strategies and expected losses in decentralized and centralized models in Figure A.1 in Appendix A.8. Comparing the six panels, we note that the total social expected damage $\left(L_{p}+L_{G}\right)$ in the centralized model is less than that in the decentralized model, and such a difference is significant when the target valuation $V$ and the probability of disaster $P_{d}$ are large, or when the investment coefficient $\gamma$ is moderate, as shown in Figure 4, panels (a)-(c). More details about the public and private strategies in comparison are shown in Figure A.1.

\section{Summary and Future Research Direction}

Since the resilience of the community is jointly determined by both the public and private sectors, and the public sector cannot deal with the disasters alone efficiently, public and private partnerships play an important role in disaster preparedness. In this paper, we study efficient public and private partnerships in both centralized and decentralized models, and we illustrate the optimal strategies with exponential and ratio damage-level function. In the decentralized model, we solve for analytical results of SPNE strategies from a sequential game model and identify the strategic complements and strategic substitute conditions for both public subsidy and private investment. From the sensitivity analyses, we find

Figure 4 (Color online) Comparison of the Public and Private Sectors' Expected Payoffs as Functions of the Target Valuations, Probability of Disaster, and Investment Effectiveness Coefficient in the Decentralized and Centralized Models

(a)

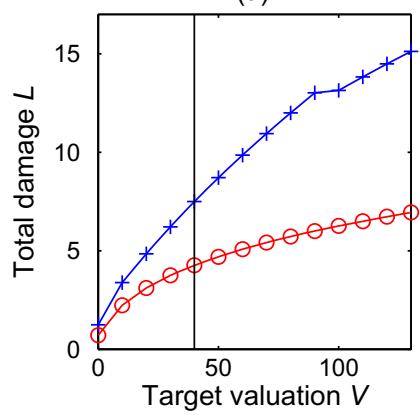

(b)

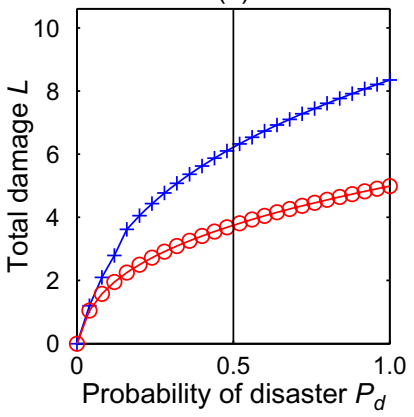

(c)

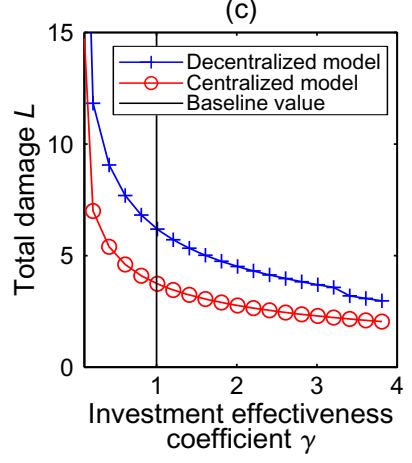


that the private sector having high target valuations in hazardous areas would have a greater potential to partner with the public sector. We also obtain the analytical solutions for the centralized model and compare them with the analytical results of the decentralized model to study the efficiency of PPPs in both models. The primary contribution of this paper is to provide insights to better understand how publicprivate partnerships can play a critical role in ensuring that private incentives are aligned with public policies under different conditions.

To our knowledge, PPPs in disaster management have not been extensively studied, especially in a quantitative manner. This paper fills this gap by studying PPPs in decentralized and centralized models. This paper focuses on a single private sector and a single public sector. In reality, the public sector would partner with multiple private sectors, which could be studied in the future. This paper studies the decision makers' decisions focusing on their expected payoffs. The decision makers' risk preferences, such as expected utility theory (von Neumann and Morgenstern 1947) and prospect theory (Tversky and Kahneman 1974, 1992; Rieger et al. 2015), could be used to study the problem in the future.

\section{Acknowledgments}

The authors thank the editor-in-chief, associate editor and two anonymous referees of Decision Analysis for constructive comments. This research was partially supported by the United States National Science Foundation (NSF) [Awards 1334930 and 1200899]. This research was also partially supported by the United States Department of Homeland Security (DHS) through the National Center for Risk and Economic Analysis of Terrorism Events (CREATE) [Award 2010-ST-061-RE0001]. However, any opinions, findings, and conclusions or recommendations in this document are those of the authors and do not necessarily reflect views of the NSF, DHS, or CREATE.

\section{Appendix}

\section{A.1. Proof of Proposition 1}

From the assumption in Equation (1), we know that $P(s, p)$ is continuous and twice differentiable. We study the convexity of the public sector's optimization problem by looking at its second partial derivatives: $\partial^{2} L_{P}(s, p) / \partial p^{2}=$ $\partial^{2}\left(P(s, p) P_{d} v\right) / \partial p^{2}=\left(\partial^{2} P(s, p) / \partial p^{2}\right) P_{d} v$. Since $\partial^{2} P(s, p) / \partial p^{2} \geq$ 0 from the assumptions in Equation (1), and $v \geq 0, P_{d} \geq 0$, we have $\partial^{2} L_{P}(s, p) / \partial p^{2} \geq 0$. Therefore, the private sector's objective function in (2) is continuous, convex, and differentiable. Thus, the following condition for an interior solution $\hat{p}(s, g)$,

$$
\frac{\partial L_{P}(s, p)}{\partial p}=P_{d} v \frac{\partial P(s, p)}{\partial p}=0,
$$

is a necessary and sufficient condition for an interior solution $p>0$. There are two possibilities of $\partial L_{P}(s, p) /\left.\partial p\right|_{p=0}=$ $P_{d} v,\left.(\partial P(s, p) / \partial p)\right|_{p=0}$.

- $\partial L_{P}(s, p) /\left.\partial p\right|_{p=0} \geq 0$ : Since $\partial^{2} L_{P}(s, p) / \partial p^{2} \geq 0$, we note that $\partial L_{P}(s, p) / \partial p$ increases in $p$. Equation (23) cannot hold for any $p>0$. Therefore, we must have a corner solution $p=0$ if $\partial L_{P}(s, p) /\left.\partial p\right|_{p=0} \geq 0$.

- $\partial L_{P}(s, p) /\left.\partial p\right|_{p=0}<0$ : Since $\partial L_{P}(s, p) / \partial p$ increases in $p$, there must exist $p>0$ such that $\partial L_{P}(s, p) / \partial p=0$. Therefore, we get an interior solution, $\left\{p: \partial L_{P}(s, p) / \partial p=0\right\}$.

\section{A.2. Proof of Proposition 2}

Similar to the proof of Proposition 1, based on the assumption of the damage rate function in Equation (1), we have $\partial^{2} L_{G}(s, p) / \partial s^{2}=\left(\partial^{2} P(s, p) / \partial s^{2}\right) P_{d} V \geq 0$. Thus, we note that the public sector's objective function in Equation (3) is continuous, twice differentiable, and convex in $s$. Therefore, the necessary conditions to have interior solutions $s^{*}>0$ are $\partial L_{G}(s, \hat{p}(s)) /\left.\partial s\right|_{s=0}<0$. Moreover, we have $s^{*}=0$ if and only if $\partial L_{G}(s, \hat{p}(s)) /\left.\partial s\right|_{s=0} \geq 0$. If $\partial L_{G}(s, \hat{p}(s)) /\left.\partial s\right|_{s=0}$ $<0$, since $L_{G}(s, p)>0$, there must exist $s>0$ such that $\partial L_{G}(s, \hat{p}(s)) / \partial s=0$. This is a contradiction. Therefore, we have the following necessary conditions for the equilibrium solutions to the public sector's optimization problem (8): (1) if $s^{*}>0$, then $\partial L_{G}(s, \hat{p}(s)) /\left.\partial s\right|_{s=0}<0$, and (2) if $s^{*}=0$, then $\partial L_{G}(s, \hat{p}(s)) /\left.\partial s\right|_{s=0} \geq 0$.

\section{A.3. Proof of Proposition 3}

We first differentiate the private sector's best response function defined in Equation (14) with respect to $s: \partial \hat{p}(s) / \partial s=$ $\left(1-\gamma-\ln \left\{P_{d} v \gamma(1+s)\right\}\right) /\left(\gamma(1+s)^{2}\right)$. If we have $\partial \hat{p}(s) / \partial s=$ $\left(1-\gamma-\ln \left\{P_{d} v \gamma(1+s)\right\}\right) /\left[\gamma(1+s)^{2}\right]>0$, then $\hat{p}(s)$ is monotonically increasing in $s$. Since $\gamma>0, s \geq 0$, we have $\gamma(1+s)^{2}>0$. Thus, $\partial \hat{p}(s) / \partial s>0 \Rightarrow 1-\gamma-\ln \left\{P_{d} v \gamma(1+s)\right\}>$ $0 \Rightarrow P_{d} v<e^{1-r} /[\gamma(1+s)]$. From the private sector's best response function in Equation (14), we note that $\hat{p}(s)$ is positive only if $P_{d} v>e^{\gamma s} /[\gamma(1+s)]$. Thus, the private sector's best response function $\hat{p}(s)$ monotonically increases in $s$ if $e^{\gamma s} /[\gamma(1+s)]<P_{d} v<e^{1-r} /[\gamma(1+s)]$. Similarly, the private sector's best response function $\hat{p}(s)$ monotonically decreases in $s$ if $P_{d} v>\max \left(e^{\gamma s} /[\gamma(1+s)], e^{1-r} /[\gamma(1+s)]\right)$.

\section{A.4. Proof of Proposition 4}

The equilibrium solutions are divided into four possible cases. For each case, the public sector's objective function is denoted as $L_{G}^{i *}$, and the feasible set is denoted as $F_{i}, \forall i=1,2,3,4$. We substitute the private sector's best response function defined in Equation (14) into the public sector's optimization problem (8) and solve for the SPNE solutions. 
- When $p^{*}>0$ : Based on the private sector's best response function in Equation (14), we have $\hat{p}^{*}\left(s^{*}\right)=$ $\left(\ln \left\{P_{d} v \gamma\left(1+s^{*}\right)\right\}-\gamma s^{*}\right) /\left[\gamma\left(1+s^{*}\right)\right]$. After substituting the private sector's best response function into the public sector's optimization problem (8), we have the public sector's objective function:

$$
\hat{L}_{G}\left(s^{*}\right)=P\left(s^{*}, \hat{p}\left(s^{*}\right)\right) P_{d} V+s^{*}=\frac{V}{\gamma v\left(1+s^{*}\right)}+s^{*} .
$$

Solving the public sector's optimization problem in Equation (24), we obtain the optimal level of public subsidy as follows:

$$
s^{*}= \begin{cases}\sqrt{\frac{V}{\gamma v}}-1 & V>\gamma v \\ 0 & V \leq \gamma v\end{cases}
$$

-When $s^{*}>0$, we have Case $1:\left(s^{*}, p^{*}\right)=(\sqrt{V /(\gamma v)}-1$, $\left.\left(\ln \left\{P_{d} \sqrt{v \gamma V}\right\}-\gamma(\sqrt{V /(\gamma v)}-1)\right) / \gamma \sqrt{V /(\gamma v)}\right)$.

Substituting the local optimizer $s^{*}$ into the public sector's objective function in Equation (24), we have $L_{G}^{1^{*}}=$ $2 \sqrt{V /(\gamma v)}-1$. According to the private sector's best response function in Equation (14) and the optimal subsidy in Equation (25), the feasible set of Case 1 is as follows:

$$
F_{1}=\left\{V>\gamma v, P_{d} v>\frac{e^{\sqrt{V /(\gamma v)}-1}}{\gamma \sqrt{V /(\gamma v)}}\right\} .
$$

-When $s^{*}=0$, we have Case $2:\left(s^{*}, p^{*}\right)=(0,(1 / \gamma)$. $\left.\ln \left\{\gamma P_{d} v\right\}\right)$.

Substituting the local optimizer $s^{*}$ into the public sector's objective function in Equation (24), we have $L_{G}^{2^{*}}=V /(\gamma v)$. According to the private sector's best response function in Equation (14) and the optimal subsidy in Equation (25), the feasible set of Case 2 is as follows:

$$
F_{2}=\left\{V \leq \gamma v, P_{d} v>\frac{1}{\gamma}\right\} \text {. }
$$

- When $p^{*}=0$, based on the private sector's best response function in Equation (14), $\hat{p}^{*}\left(s^{*}\right)=0$. After substituting the private sector's best response function (14) into the public sector's optimization problem (8), we have the public sector's objective function:

$$
\begin{aligned}
\hat{L}_{G}(s)=P\left(s^{*}, \hat{p}\left(s^{*}\right)\right) P_{d} V+s^{*} & =\exp \left[-\gamma\left(s^{*}+0+0 \cdot s^{*}\right)\right] P_{d} V+s^{*} \\
& =\exp \left[-\gamma s^{*}\right] P_{d} V+s^{*} .
\end{aligned}
$$

Solving the public sector's optimization problem in Equation (28), we obtain the optimal level of public subsidy as follows:

$$
s^{*}= \begin{cases}\frac{1}{\gamma} \ln \left\{\gamma P_{d} V\right\} & V>\frac{1}{\gamma P_{d}}, \\ 0 & V \leq \frac{1}{\gamma P_{d}} .\end{cases}
$$

-If $s^{*}>0$, we have Case 3: $\left(s^{*}, p^{*}\right)=\left((1 / \gamma) \ln \left\{\gamma P_{d} V\right\}, 0\right)$.
Substituting the local optimizer $s^{*}$ into the public sector's objective function in Equation (28), we have $L_{G}^{3^{*}}=$ $(1 / \gamma)\left(1 / P_{d} V+\ln \left\{\gamma P_{d} V\right\}\right)$. According to the private sector's best response function in Equation (14) and the optimal subsidy in Equation (29), the feasible set of Case 3 is as follows:

$$
F_{3}=\left\{V>\frac{1}{\gamma P_{d}}, P_{d} v \leq \frac{P_{d} V}{\ln \left\{\gamma P_{d} V\right\}}\right\} .
$$

-If $s^{*}=0$, we have Case $4:\left(s^{*}, p^{*}\right)=(0,0)$. Substituting the local optimizer $s^{*}$ into the public sector's objective function in Equation (28), we have $L_{G}^{4^{*}}=P_{d} V$. According to the private sector's best response function in Equation (14) and the optimal subsidy in Equation (29), the feasible set of Case 4 is as follows:

$$
F_{4}=\left\{V \leq \frac{1}{\gamma P_{d}}, P_{d} v \leq \frac{1}{\gamma}\right\}
$$

According to all the feasible set $F_{i}$, we can have Case $i$ to be optimal if $F_{i} \cap F_{j}=\varnothing$ or if $F_{i} \cap F_{j} \neq \varnothing$ and $L_{G}^{i^{*}} \leq L_{G}^{j}, \forall i, j=$ $1,2,3,4, i \neq j$. Therefore, the optimal range of Case $i$ is defined as $O_{i} \equiv \bigcap_{i, j=1,2,3,4, i \neq j}\left\{\left\{F_{i} \cap F_{j} \cap\left\{L_{G}^{i^{*}} \leq L_{G}^{j^{*}}\right\}\right\} \cup\left\{F_{i} \cap \bar{F}_{j}\right\}\right\}$.

Since the feasible sets of Cases 1 and 2 are complements to each other, as well as the feasible set of Cases 3 and 4, the intersection of the feasible sets in Cases 1 and 2 and the intersection of the feasible sets in Cases 3 and 4 are empty sets. So we do not consider the comparison between Cases 1 and 2 and Cases 3 and 4 in the optimal conditions. Since we assume that if the public sector would not invest if it is indifferent between investing and not investing, then the public would choose the strategies in Cases 1 and 3 if the corresponding expected losses are strictly less than other cases in which the public sector provides zero subsidy.

Thus, if all the conditions $O_{i}, \forall i=1,2,3,4$ in Equation (32) hold, then $\left(s^{*}, p^{*}\right)$ are the equilibrium strategies for both public and private sectors:

Case 1: $\left(s^{*}, p^{*}\right)=\left(\sqrt{\frac{V}{\gamma v}}-1, \frac{\ln \left\{P_{d} \sqrt{v \gamma V}\right\}-\gamma(\sqrt{V /(\gamma v)}-1)}{\gamma \sqrt{V /(\gamma v)}}\right)$

Case 2: $\left(s^{*}, p^{*}\right)=\left(0, \frac{1}{\gamma} \ln \left\{\gamma P_{d} v\right\}\right)$ if $O_{2}$,

Case 3: $\left(s^{*}, p^{*}\right)=\left(\frac{1}{\gamma} \ln \left\{\gamma P_{d} V\right\}, 0\right)$ if $O_{3}$,

Case 4: $\left(s^{*}, p^{*}\right)=(0,0)$ if $O_{4}$,

where the optimal set $O_{i}, i=1,2,3,4$ is calculated as

$$
\begin{aligned}
O_{1}= & \left\{\left\{F_{1} \cap F_{3} \cap\left\{2 \sqrt{\frac{V}{\gamma v}}-1<\frac{1}{\gamma}\left(\frac{1}{P_{d} V}+\ln \left\{\gamma P_{d} V\right\}\right)\right\}\right\}\right. \\
& \left.\cup\left\{F_{1} \cap \bar{F}_{3}\right\}\right\} \\
& \cap\left\{\left\{F_{1} \cap F_{4} \cap\left\{2 \sqrt{\frac{V}{\gamma v}}-1<P_{d} V\right\}\right\} \cup\left\{F_{1} \cap \bar{F}_{4}\right\}\right\},
\end{aligned}
$$




$$
\begin{aligned}
\mathrm{O}_{2}= & \left\{\left\{F_{2} \cap F_{3} \cap\left\{\frac{V}{\gamma v} \leq \frac{1}{\gamma}\left(\frac{1}{P_{d} V}+\ln \left\{\gamma P_{d} V\right\}\right)\right\}\right\} \cup\left\{F_{2} \cap \bar{F}_{3}\right\}\right\} \\
& \cap\left\{\left\{F_{2} \cap F_{4} \cap\left\{\frac{V}{\gamma v} \leq P_{d} V\right\}\right\} \cup\left\{F_{2} \cap \bar{F}_{4}\right\}\right\}, \\
O_{3}= & \left\{\left\{F_{3} \cap F_{1} \cap\left\{\frac{1}{\gamma}\left(\frac{1}{P_{d} V}+\ln \left\{\gamma P_{d} V\right\}\right)<2 \sqrt{\frac{V}{\gamma v}}-1\right\}\right\}\right. \\
& \left.\cup\left\{F_{3} \cap \bar{F}_{1}\right\}\right\} \cap\left\{\left\{F_{3} \cap F_{2} \cap\left\{\frac{1}{\gamma}\left(\frac{1}{P_{d} V}+\ln \left\{\gamma P_{d} V\right\}\right)<\frac{V}{\gamma v}\right\}\right\}\right. \\
& \left.\cup\left\{F_{3} \cap \bar{F}_{2}\right\}\right\}, \\
O_{4}= & \left\{\left\{F_{4} \cap F_{1} \cap\left\{P_{d} V \leq 2 \sqrt{\frac{V}{\gamma v}}-1\right\}\right\} \cup\left\{F_{4} \cap \bar{F}_{1}\right\}\right\} \\
& \cap\left\{\left\{F_{4} \cap F_{2} \cap\left\{P_{d} V \leq \frac{V}{\gamma v}\right\}\right\} \cup\left\{F_{4} \cap \bar{F}_{2}\right\}\right\},
\end{aligned}
$$

where $F_{i}$ is the feasible set for the SPNE of Case $i(i=1,2$, $3,4)$, which is defined in Equations (26), (27), (30), and (31), respectively.

\section{A.5. Proof of Proposition 5}

The SPNE solutions of the decentralized model with the ratio damage ratio function can be divided into four possible cases. For each case, we denote the public sector's objective function as $L_{G}^{i^{*}}$ and the corresponding feasible set as $F_{i}^{r}, \forall i=1,2,3,4$. We substitute the private sector's best response function in Equation (17) into the public sector's optimization problem and solve for the SPNE solutions. To simplify the problem, we let $A=1$.

- When $p^{*}>0$ : According to the private sector's sector's best response function in Equation (17), we have $\hat{p}^{*}\left(s^{*}\right)=$ $\sqrt{P_{d} v /\left(\gamma\left(1+s^{*}\right)\right)}-1$, the public sector's objective function, as follows:

$$
\hat{L}_{G}\left(s^{*}\right)=P\left(s^{*}, \hat{p}\left(s^{*}\right)\right) P_{d} V+s^{*}=V \sqrt{\frac{P_{d}}{\gamma v\left(1+s^{*}\right)}}+s^{*} .
$$

Solving the public sector's optimization problem in Equation (37), we obtain the optimal level of public subsidy as follows:

$$
s^{*}= \begin{cases}\sqrt[3]{\frac{V^{2} P_{d}}{4 \gamma v}}-1 & P_{d}>\frac{4 v}{V^{2}}, \\ 0 & P_{d} \leq \frac{4 v}{V^{2}} .\end{cases}
$$

-If $s^{*}>0$, we have Case $1:\left(s^{*}, p^{*}\right)=\left(\sqrt[3]{V^{2} P_{d} /(4 \gamma v)}-1\right.$, $\left.\sqrt[3]{2 v^{2} P_{d} /(\gamma V)}-1\right)$. Substituting the local optimizer $s^{*}$ into the public sector's objective function in Equation (37), we have

$$
L_{G}^{1^{*}}=\sqrt[3]{\frac{2 P_{d} V^{2}}{\gamma v}}+\sqrt[3]{\frac{V^{2} P_{d}}{4 \gamma v}}-1
$$

According to the private sector's best response function in Equation (17) and the optimal subsidy in Equation (38), the feasible set of Case 1 is as follows:

$$
F_{1}^{r}=\left\{P_{d}>\max \left\{\frac{4 v}{V^{2}}, \frac{\gamma V}{2 v^{2}}\right\}\right\} .
$$

-If $s^{*}=0$, we have Case $2:\left(s^{*}, p^{*}\right)=\left(0, \sqrt{P_{d} v / \gamma}-1\right)$. Substituting the local optimizer $s^{*}$ into the public sector's objective function in Equation (37), we have

$$
L_{G}^{2^{*}}=\sqrt{\frac{P_{d} V}{\gamma v}} .
$$

According to the private sector's best response function in Equation (17) and the optimal subsidy in Equation (38), the feasible set of Case 2 is as follows:

$$
F_{2}^{r}=\left\{\frac{\gamma}{v}<P_{d} \leq \frac{4 v}{V^{2}}\right\}
$$

- When $p^{*}=0$ : According to the private sector's best response function in Equation (17), we have $\hat{p}^{*}\left(s^{*}\right)=0$. After substituting the private sector's best response function (17) into the public sector's optimization problem, we have the public sector's objective function as follows:

$$
\hat{L}_{G}(s)=P\left(s^{*}, \hat{p}\left(s^{*}\right)\right) P_{d} V+s^{*}=\frac{P_{d} V}{\gamma\left(1+s^{*}\right)}+s^{*} .
$$

Solving the public sector's optimization problem in Equation (43), we obtain the optimal level of public subsidy as follows:

$$
s^{*}= \begin{cases}\sqrt{\frac{P_{d} V}{\gamma}-1} & P_{d}>\frac{\gamma}{V}, \\ 0 & P_{d} \leq \frac{\gamma}{V},\end{cases}
$$

-If $s^{*}>0$, we have Case 3: $\left(s^{*}, p^{*}\right)=\left(\sqrt{P_{d} V / \gamma}-1,0\right)$. Substituting the local optimizer $s^{*}$ into the public sector's objective function in Equation (43), we have

$$
L_{G}^{3^{*}}=2 \sqrt{\frac{P_{d} V}{\gamma}}-1
$$

According to the private sector's best response function in Equation (17) and the optimal subsidy in Equation (44), the feasible set of Case 3 is as follows:

$$
F_{3}^{r}=\left\{\frac{\gamma}{V}<P_{d} \leq \frac{\sqrt{\gamma P_{d} V}}{v}\right\} .
$$

-If $s^{*}=0$, we have Case $4:\left(s^{*}, p^{*}\right)=(0,0)$. Substituting the local optimizer $s^{*}$ into the public sector's objective function in Equation (43), we have

$$
L_{G}^{4^{*}}=P_{d} V \text {. }
$$

According to the private sector's best response function in Equation (17) and the optimal subsidy in Equation (44), the feasible set of Case 4 is as follows:

$$
F_{4}^{r}=\left\{P_{d} \leq \min \left\{\frac{\gamma}{V}, \frac{\gamma}{v}\right\}\right\}
$$


According to all the feasible sets $F_{i}^{r}$, we can have Case $i$ be optimal if $F_{i}^{r} \cap F_{j}^{r}=\varnothing$ or if $F_{i}^{r} \cap F_{j}^{r} \neq \varnothing$ and $L_{G}^{i^{*}} \leq L_{G}^{j}$, $\forall i, j=1,2,3,4, i \neq j$. Therefore, the optimal range of Case $i$ is defined as $O_{i}^{r} \equiv \bigcap_{i, j=1,2,3,4, i \neq j}\left\{\left\{F_{i}^{r} \cap F_{j}^{r} \cap\left\{L_{G}^{i^{*}} \leq L_{G}^{j^{*}}\right\}\right\} \cup\right.$ $\left.\left\{F_{i}^{r} \cap \bar{F}_{j}^{r}\right\}\right\}$.

Since the feasible sets of Cases 1 and 2 are complements to each other as well as the feasible set of Cases 3 and 4, the intersection feasible sets of Cases 1 and 2 and of Cases 3 and 4 are empty sets. Therefore, we do not consider the comparison between Cases 1 and 2 and Cases 3 and 4 in the optimal conditions. Since we assume that if the public sector would not invest if it is indifferent between investing and not investing, then the public would choose the strategies in Cases 1 and 3 if the corresponding expected losses are strictly less than those in other cases in which the public sector provides zero subsidy.

Thus, the equilibrium strategies of both public and private sectors $\left(s^{*}, p^{*}\right)$ are as follows:

Case 1: $\left(s^{*}, p^{*}\right)=\left(\sqrt[3]{\frac{V^{2} P_{d}}{4 \gamma v}}-1, \sqrt[3]{\frac{2 v^{2} P_{d}}{\gamma V}}-1\right)$ if $O_{1}^{r}$,

Case 2: $\left(s^{*}, p^{*}\right)=\left(0, \sqrt{\frac{P_{d} v}{\gamma}}-1\right)$ if $O_{2}^{r}$,

Case 3: $\left(s^{*}, p^{*}\right)=\left(\sqrt{\frac{P_{d} V}{\gamma}}-1,0\right)$ if $O_{3}^{r}$,

Case 4: $\left(s^{*}, p^{*}\right)=(0,0)$ if $O_{4}^{r}$,

where the optimal set $O_{i}^{r}, i=1,2,3,4$ is calculated as

$$
\begin{aligned}
& O_{1}^{r}=\left\{\begin{array}{c}
\left\{\left\{F_{1}^{r} \cap F_{3}^{r} \cap\left\{L_{G}^{1^{*}}<L_{G}^{3^{*}}\right\}\right\} \cup\left\{F_{1}^{r} \cap \bar{F}_{3}^{r}\right\}\right\}, \\
\cap\left\{\left\{F_{1}^{r} \cap F_{4}^{r} \cap\left\{L_{G}^{1^{*}}<L_{G}^{4^{*}}\right\}\right\} \cup\left\{F_{1}^{r} \cap \bar{F}_{4}^{r}\right\}\right\},
\end{array}\right. \\
& O_{2}^{r}=\left\{\begin{array}{c}
\left\{\left\{F_{2}^{r} \cap F_{3}^{r} \cap\left\{L_{G}^{2^{*}} \leq L_{G}^{3^{*}}\right\}\right\} \cup\left\{F_{2}^{r} \cap \bar{F}_{3}^{r}\right\}\right\}, \\
\cap\left\{\left\{F_{2}^{r} \cap F_{4}^{r} \cap\left\{L_{G}^{2^{*}} \leq L_{G}^{4^{*}}\right\}\right\} \cup\left\{F_{2}^{r} \cap \bar{F}_{4}^{r}\right\}\right\},
\end{array}\right. \\
& O_{3}^{r}=\left\{\begin{array}{c}
\left\{\left\{F_{3}^{r} \cap F_{1}^{r} \cap\left\{L_{G}^{3^{*}}<L_{G}^{1^{*}}\right\}\right\} \cup\left\{F_{3}^{r} \cap \bar{F}_{1}^{r}\right\}\right\}, \\
\cap\left\{\left\{F_{3}^{r} \cap F_{2}^{r} \cap\left\{L_{G}^{3^{*}}<L_{G}^{2^{*}}\right\}\right\} \cup\left\{F_{3}^{r} \cap \bar{F}_{2}^{r}\right\}\right\},
\end{array}\right. \\
& O_{4}^{r}=\left\{\begin{array}{c}
\left\{\left\{F_{4}^{r} \cap F_{1}^{r} \cap\left\{L_{G}^{4^{*}} \leq L_{G}^{1^{*}}\right\}\right\} \cup\left\{F_{4}^{r} \cap \bar{F}_{1}^{r}\right\}\right\}, \\
\cap\left\{\left\{F_{4}^{r} \cap F_{2}^{r} \cap\left\{L_{G}^{4^{*}} \leq L_{G}^{2^{*}}\right\}\right\} \cup\left\{F_{4}^{r} \cap \bar{F}_{2}^{r}\right\}\right\},
\end{array}\right.
\end{aligned}
$$

where $F_{i}^{r}$ is the feasible set for the SPNE of Case $i$ and $L_{G}^{i^{*}}$ is the corresponding public sector's objective $(i=1,2,3,4)$, which is defined in Equations (40), (42), (46), and (48) and Equations (39), (41), (45), and (47), respectively.

\section{A.6. Proof of Proposition 6}

According to the assumption of the damage rate functions in $\S 2$, such functions are continuous and twice differentiable with diminishing marginal effects in both public and private investments: $\partial^{2} P(s, p) / \partial p^{2} \geq 0, \partial^{2} P(s, p) / \partial s^{2} \geq 0$. Based on the private sector's optimization model (2) and public sector's optimization model (3), we have

$$
\begin{aligned}
& \frac{\partial^{2} L_{P}(s, p)}{\partial p^{2}}=\frac{\partial^{2} P(s, p)}{\partial p^{2}} P_{d} v \geq 0, \\
& \frac{\partial^{2} L_{P}(s, p)}{\partial s^{2}}=\frac{\partial^{2} P(s, p)}{\partial s^{2}} P_{d} v \geq 0, \\
& \frac{\partial^{2} L_{G}(s, p)}{\partial s^{2}}=\frac{\partial^{2} P(s, p)}{\partial s^{2}} P_{d} V \geq 0, \\
& \frac{\partial^{2} L_{G}(s, p)}{\partial p^{2}}=\frac{\partial^{2} P(s, p)}{\partial p^{2}} P_{d} V \geq 0 .
\end{aligned}
$$

Note that $P_{d}, v$, and $V$ are nonnegative. Thus, for the centralized model, we have

$$
\begin{aligned}
& \frac{\partial^{2} L(s, p)}{\partial p^{2}}=\frac{\partial^{2} L_{P}(s, p)}{\partial p^{2}}+\frac{\partial^{2} L_{G}(s, p)}{\partial p^{2}} \geq 0, \\
& \frac{\partial^{2} L(s, p)}{\partial s^{2}}=\frac{\partial^{2} L_{P}(s, p)}{\partial s^{2}}+\frac{\partial^{2} L_{G}(s, p)}{\partial s^{2}} \geq 0 .
\end{aligned}
$$

Therefore, similar to the proof of Propositions 1 and 2, we have the necessary conditions for the solution to the public and private sectors' optimal solution in Equation (20) as follows: (1) if $s^{* *}>0$, then $\partial L\left(s, p^{* *}\right) /\left.\partial s\right|_{s=0}<0$; (2) if $p^{* *}>0$, then $\partial L\left(s^{* *}, p\right) /\left.\partial p\right|_{p=0}<0$; (3) if $s^{* *}=0$, then $\partial L\left(s, p^{* *}\right) /\left.\partial s\right|_{s=0} \geq 0$; and (4) if $p^{* *}=0$, then $\partial L\left(s^{* *}, p\right) /\left.\partial p\right|_{p=0} \geq 0$.

\section{A.7. Proof of Proposition 7}

Since both the public and private sectors' optimizations are convex, according to the first-order condition, the corresponding optimal solutions to the social planner problem can be obtained by solving the system equations in Equation (54):

$$
\left\{\begin{array} { l } 
{ \frac { \partial L ( s , p ) } { \partial p } = 0 } \\
{ \frac { \partial L ( s , p ) } { \partial s } = 0 }
\end{array} \Longrightarrow \left\{\begin{array}{l}
\frac{1}{\gamma(1+s)(1+p)^{2}}=\frac{1}{P_{d} V} \\
\frac{1}{\gamma(1+s)^{2}(1+p)}=\frac{1}{P_{d} V} .
\end{array}\right.\right.
$$

Since $s$ and $p$ are nonnegative, the optimal solution to the system equation in Equation (54) is as follows:

$$
\begin{gathered}
s^{* *}= \begin{cases}\sqrt[3]{\frac{P_{d} V}{\gamma}-1} & P_{d}>\frac{\gamma}{V}, \\
0 & P_{d} \leq \frac{\gamma}{V}\end{cases} \\
p^{* *}= \begin{cases}\sqrt[3]{\frac{P_{d} V}{\gamma}-1} & P_{d}>\frac{\gamma}{V} \\
0 & P_{d} \leq \frac{\gamma}{V} .\end{cases}
\end{gathered}
$$

- When $s^{* *}>0, p^{* *}>0$, then we have Case 1: $\left(s^{* *}, p^{* *}\right)=$ $\left(\sqrt[3]{P_{d} V / \gamma}-1, \sqrt[3]{P_{d} V / \gamma}-1\right)$, under the condition of $P_{d}>\gamma / V$. 
Figure A.1 (Color online) Comparison of the Public and Private Sectors' Strategy and Expected Payoffs as Functions of the Private and Public Target Valuations, Private and Public Investment Cost Coefficients, Investment Effectiveness Coefficient, and Probability of Disaster in the Decentralized and the Centralized Models

$\left(a_{1}\right)$ Decentralized model
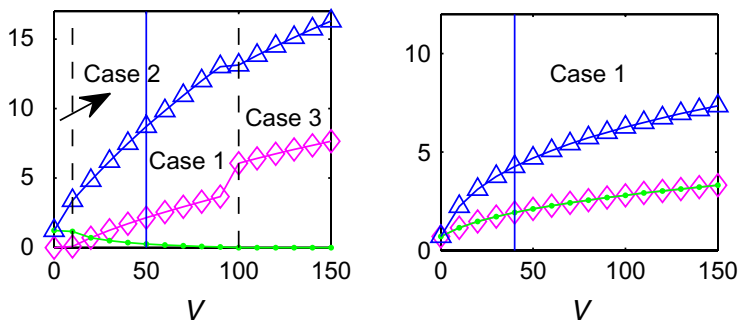

$\left(\mathrm{c}_{1}\right)$ Decentralized model

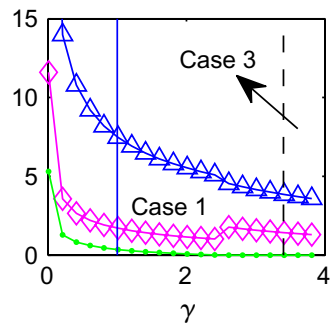

$\left(b_{1}\right)$ Decentralized model

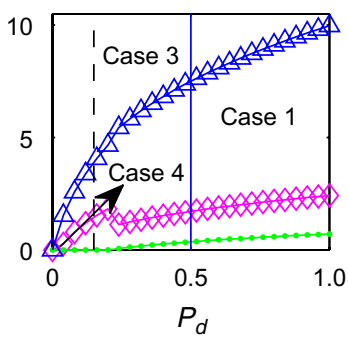

$\left(b_{2}\right)$ Centralized model

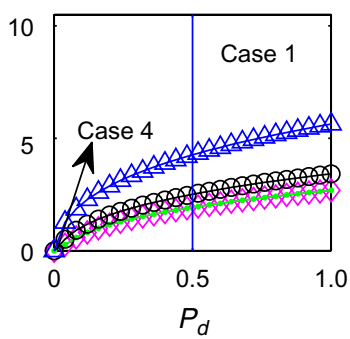

$\left(c_{2}\right)$ Centralized model

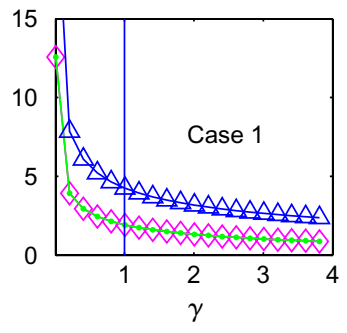

$\diamond$ Public subsidy $s \longrightarrow$ Private investment $p \longrightarrow \triangle$ Total damage $L$

Baseline value

- When $s^{* *}=0, p^{* *}>0$, we rewrite the social planner's problem in Equation (20), and we have

$$
\left(s^{* *}, p^{* *}\right)=\underset{p \geq 0, s=0}{\arg \min } L(s, p)=\frac{P_{d} V}{r(1+p)}+p .
$$

After solving the optimization problem in Equation (57), we have Case $2:\left(s^{* *}, p^{* *}\right)=\left(0, \sqrt{P_{d} V / \gamma}-1\right)$, under the condition of $P_{d}>\gamma / V$.

From Equation (55), we note that the condition $P_{d} \leq \gamma / V$ should hold if $s^{* *}=0$. Thus, Case $2\left(s^{* *}=0, p^{* *}>0\right)$ does not exist.

- When $s^{* *}>0, p^{* *}=0$, we rewrite the social planner's problem in Equation (20); then we have

$$
\left(s^{* *}, p^{* *}\right)=\underset{p=0, s>0}{\arg \min } L(s, p)=\frac{P_{d} V}{r(1+s)}+s .
$$

After solving the optimization problem in Equation (58), we have Case 3: $\left(s^{* *}, p^{* *}\right)=\left(\sqrt{P_{d} V / \gamma}-1,0\right)$, under the condition of $P_{d}>\gamma / V$.

From Equation (56), we note that the condition $P_{d} \leq \gamma / V$ should hold if $p^{* *}=0$. Thus, Case $3\left(s^{* *}>0, p^{* *}=0\right)$ does not exist.

- When $s^{* *}=0, p^{* *}=0$, the condition of Case 4 is $P_{d} \leq \gamma / V$.

\section{A.8. Detailed Comparison of the Decentralized and Centralized Models}

We graphically depict the comparison between the decentralized and centralized models in Figure A.1.

\section{References}

Adida E, DeLaurentis PCC, Lawley MA (2011) Hospital stockpiling for disaster planning. IIE Trans. 43(5):348-362.

Amin M (2004) Balancing market priorities with security issues. IEEE Power Energy Magazine 2(4):30-38.

August T, Tunca TI (2006) Network software security and user incentives. Management Sci. 52(11):1703-1720.

Azaiez MN, Bier VM (2007) Optimal resource allocation for security in reliability systems. Eur. J. Oper. Res. 181(2):773-786.

Bier VM, Haphuriwat N, Menoyo J, Zimmerman R, Culpen AM (2008) Optimal resource allocation for defense of targets based on differing measures of attractiveness. Risk Anal. 28(3): 763-770.

Blanc-Brude F, Goldsmith H, Välilä T (2008) Public-private partnerships in Europe: An update. Economic and Investment Report 2007/03, European Investment Bank, Luxembourg. http://www.eib.org/attachments/efs/efr_2007_v03_en.pdf.

Briceno S (2009) International strategy for disaster reduction. The Future of Drylands (Springer, Berlin), 25-28.

Brown G, Carlyle M, Salmerón J, Wood K (2006) Defending critical infrastructure. Interfaces 36(6):530-544.

Brown G, Carlyle M, Diehl D, Kline J, Wood K (2005) A twosided optimization for theater ballistic missile defense. Oper. Res. 53(5):745-763. 
Busch NE, Givens AD (2012) Public-private partnerships in homeland security: Opportunities and challenges. Homeland Security Affairs 8(1):1-24.

Cheung M, Zhuang J (2012) Regulation games between government and competing companies: Oil spills and other disasters. Decision Anal. 9(2):156-164.

Committee on Private-Public Sector Collaboration to Enhance Community Disaster Resilience, National Research Council (2012) Building Community Disaster Resilience Through Private-Public Collaboration (National Academies Press, Washington, DC).

Dearden L, Emmerson C, Frayne C, Meghir C (2005) Can education subsidies stop school drop-outs? An evaluation of education maintenance allowances in England. Presentation at the American Economic Association Annual Meeting, January 7, American Economic Association, Nashville, TN. http://www.aeanet.org/annual_mtg_papers/2005/0107_0800_0801.pdf.

United States Government Accountability Office (2006) GAO-07-39 critical infrastructure protection coordination issues. Accessed February 2015, http:/ /www.gao.gov/assets/260/252603.pdf.

Dodgson JS (1986) Benefits of changes in urban public transport subsidies in the major Australian cities. Econom. Record 62(2):224-235.

Federal Emergency Management Agency (2013) Expanding the team: Private sector collaboration with FEMA. Federal Emergency Management Agency, Washington, DC. http://www .fema.gov/media-library/assets/documents/85302.

Flynn SE (2007) The Edge of Disaster: Rebuilding a Resilient Nation (Random House, New York).

Flynn SE (2008) America the resilient: Defying terrorism and mitigating natural disasters. Foreign Affairs 87(2):2-8.

Fudenberg D, Tirole J (1991) Game Theory (MIT Press, Cambridge, MA).

Golalikhani M, Zhuang J (2011) Modeling arbitrary layers of continuous-level defenses in facing with strategic attackers. Risk Anal. 31(4):533-547.

Grace MF, Klein RW, Kleindorfer PR, Murray MR (2003) Catastrophe Insurance: Consumer Demand, Markets, and Regulation (Springer, New York).

Gruber J, Levitt L (2011) Tax subsidies for health insurance: Costs and benefits. Health Affairs 19(1):72-85.

Hansen WL (1983) Impact of student financial aid on access. Proc. Acad. Political Sci. 35(2):84-96.

Hao M, Jin S, Zhuang J (2009) Robustness of optimal defensive resource allocations in the face of less than fully rational attackers. Proc. 2009 Indust. Engrg. Res. Conf., Institute of Industrial Engineers, Norcross, GA, 886-891.

Hausken K (2008) Strategic defense and attack for series and parallel reliability systems. Eur. J. Oper. Res. 186(2):856-881.

Hausken K, Zhuang J (2012) The timing and deterrence of terrorist attacks due to exogenous dynamics. J. Oper. Res. Soc. 63(6): 790-809.

Hausken K, Bier VM, Zhuang J (2008) Defending against terrorism, natural disaster, and all hazards. Bier VM, Azaiez MN, eds. Game Theoretic Risk Analysis of Security Threats (Springer, New York), 65-97.

Hayes JK, Ebinger CK (2011) The private sector and the role of risk and responsibility in securing the nation's infrastructure. J. Homeland Security Emergency Management 8(1):Article 13.

Keohane NO, Zeckhauser RJ (2003) The ecology of terror defense. J. Risk Uncertainty 26(2-3):201-229.

Kim V (2011) Japan damage could reach \$235 billion, World Bank estimates. Los Angeles Times (March 21), http://articles latimes.com/2011/mar/21/world/la-fgw-japan-quake-world -bank-20110322.
Kriechel B, Ziesemer T (2009) The environmental porter hypothesis: Theory, evidence, and a model of timing of adoption. Econom. Innovation New Tech. 18(3):267-294.

Kunreuther H (2002) The role of insurance in managing extreme events: Implications for terrorism coverage. Risk Anal. 22(3):427-437.

Lindell MK, Perry RW (2000) Household adjustment to earthquake hazard a review of research. Environ. Behav. 32(4):461-501.

Lindell MK, Whitney DJ (2000) Correlates of household seismic hazard adjustment adoption. Risk Anal. 20(1):13-26.

McMillan J (2003) Reinventing the Bazaar: A Natural History of Markets (W. W. Norton \& Company, New York).

Myerson RB (1997) Game Theory: Analysis of Conflict (Harvard University Press, Cambridge, MA).

National Consortium for the Study of Terrorism and Responses to Terrorism (2014) Global Terrorism Database: Incidents over time. Accessed February 2015, http://www.start.umd.edu/gtd.

National Police Agency (2015) Damage situation and police countermeasures associated with 2011 Tohoku district-off the Pacific Ocean Earthquake. Report, National Police Agency, Tokyo. http://www.npa.go.jp/archive/keibi/biki/higaijokyo e.pdf.

Norris FH, Stevens SP, Pfefferbaum B, Wyche KF, Pfefferbaum RL (2008) Community resilience as a metaphor, theory, set of capacities, and strategy for disaster readiness. Amer. J. Community Psych. 41(1):127-150.

Nushiwat M (2007) Foreign aid to developing countries: Does it crowd-out the recipient countries' domestic savings? Internat. Res. J. Finance Econom. 11:93-101.

Patrinos HA, Sosale S (2007) Mobilizing the Private Sector for Public Education: A View from the Trenches (World Bank Publications, Washington, DC).

RAND (2015) Community resilience. Accessed February 2015, http://www.rand.org/topics/community-resilience.html.

Rieger MO, Wang M, Hens T (2015) Risk preferences around the world. Management Sci. 61(3):637-648.

Samuel A, Guikema SD (2012) Resource allocation for homeland defense: Dealing with the team effect. Decision Anal. 9(3): 238-252.

Schultz TP (2004) School subsidies for the poor: Evaluating the Mexican Progresa poverty program. J. Development Econom. 74(1):199-250.

Shan X, Zhuang J (2014) Modeling credible retaliation threats in deterring the smuggling of nuclear weapons using partial inspection-A three-stage game. Decision Anal. 11(1):43-62.

Shubik M (1955) The uses of game theory in management science. Management Sci. 2(1):40-54.

Tversky A, Kahneman D (1974) Judgment under uncertainty: Heuristics and biases. Science 185(4157):1124-1131.

Tversky A, Kahneman D (1992) Advances in prospect theory: Cumulative representation of uncertainty. J. Risk Uncertainty 5(4):297-323.

U.S. Coast Guard (2011) On scene coordinator report: Deepwater Horizon oil spill. Report submitted to National Response Team, U.S. Coast Guard, Washington, DC. http://www.uscg.mil/ foia/docs/dwh/fosc_dwh_report.pdf.

U.S. Government Accountability Office (2006) GAO-07-39 critical infrastructure protection coordination issues. Accessed February 2015, http://www.gao.gov/assets/260/252603.pdf.

von Neumann J, Morgenstern O (1947) Theory of Games and Economic Behavior (Princeton University, Princeton, NJ).

Wang C, Bier VM (2011) Target-hardening decisions based on uncertain multiattribute terrorist utility. Decision Anal. 8(4): 286-302.

Webster M, Ginnetti J, Walker P, Coppard D, Kent R (2009) The Humanitarian Costs of Climate Change (Feinstein International Center, Medford, MA). 
Zhuang J (2010) Impacts of subsidized security on stability and total social costs of equilibrium solutions in an $n$-player game with errors. Engrg. Economist 55(2):131-149.

Zhuang J, Bier VM (2007) Balancing terrorism and natural disasters-Defensive stratey with endogenous attacker effort. Oper. Res. 55(5):976-991.

Peiqiu Guan is a doctoral candidate in the Department of Industrial and Systems Engineering at the University at Buffalo, State University of New York. She holds an M.Phil. in risk management science from the Chinese University of Hong Kong and a B.S. in information and computing science from Jinan University. Her research interests include mathematical modeling, game theory, optimization, risk measure, operations research, model validation, and applications to risk and disaster management.

Jun Zhuang is an associate professor of industrial and systems engineering at the University at Buffalo, State University of New York. He has a Ph.D. from the University of Wisconsin-Madison, an M.S. from the University of Kentucky, and a bachelor's degree from Southeast University, China. His long-term research goal is to integrate operations research, game theory, and decision analysis to improve mitigation, preparedness, response, and recovery for natural and man-made disasters. 